\title{
Operations in the context of urban mobility: Evaluating the Performance of the Deliveries to Small Retailers
}

\author{
João Victor Rodrigues Silva \\ martins@cepead.face.ufmg.br \\ Center for Graduate Studies and Research in Business Administration (CEPEAD)/Federal University of Minas Gerais (UFMG)
}

\section{Ricardo Silveira Martins \\ martins@cepead.face.ufmg.br \\ UFMG}

ABSTRACT: This study aims to clarify the performance attributes of logistical service that retailers identify as more relevant to their suppliers' distribution process in urban areas. And, this task was performed using the Stated Preference Technique, a tool not so widespread among operations management researchers. The research focused the small retail food stores in Belo Horizonte, Brazil, considering the complexity involved in the delivery of perishable and fragile foods. As result, the technique show us the relative importance of the attributes related to the service level, highlighting the high degree of relevance achieved by the attributes that define the service level. This means that gaps in services are not easily shadowed by compensatory practices of stock build-up, which are financially very burdensome or unviable in terms of storage area. This kind of approach may call attention to opportunities of improving buyer-supplier relationships and the management of these processes, as well as public issues.

Key words: Small retailer, Urban distribution, Supply performance, Stockout. 


\section{INTRODUCTION}

The urban concentration creates problems related to the urban mobility of people and decline in the quality of life, and hinders the supply of commercial establishments. In the similar context, the delivery process related to the handling of products also poses some challenges. The effects can be perceived in different ways, from increased costs to quality of services. The increase in costs can be attributed to a number of factors like, the need for an expanded fleet, smaller orders in more frequent batches, and the formation of a higher level of safety stock. Meanwhile, the quality of service may fall, for example, measured by the number of deliveries delayed.

Beyond that, as the problem of mobility in urban centers worsens, these effects become more harmful for customers and retailers. To the end customer, the most perceived results are an increase in prices and a decrease in the availability and variety of products on the shelves. For the retailer, in particular, the level of service, the rising costs, and the customers' reactions to such situations results in a loss of sales and a decline in business profitability (Ali 2011; Aastrup \& Kotzab 2010).

Retail companies, on daily basis, experience complex situations, involving challenges to provide their customers with a level of service that is consistent with expectations, while at the same time, at controlled costs. This requires a greater capacity in logistical planning, along with efforts in the traditional areas, such as marketing, finance, and customer service. Planning, executing, monitoring, measuring, and controlling the performance of logistical operations in large urban centers is the key for success in the food retail segment as it involves direct contact with the end consumer.

Moreover, it is customary for suppliers to lack clear information regarding the actual needs and wants of retailers. Some authors not only demonstrate that customers are interested in more than just costs, but also highlight the need to investigate other attributes linked to service (Ballou 2004; Bowersox, Closs \& Cooper 2002; Chopra \& Meindl 2007).

Therefore, this study aims to clarify the performance attributes of logistical service that retail businesses identify as more relevant to their suppliers' distribution process in urban areas. And, this task was performed using the Stated Preference Technique, a tool useful for leading with this kind of phenomenon, since we can analyze scenarios devised by the respondents so that they make the trade-offs between attributes of service, but not so widespread among operations management researchers.

To deal with this question, it is first necessary to create mechanisms that would help identify which are the needs of retailers in relation to their partners, so that consumers receive higher added value. Therefore, the knowledge of logistical performance indicators is an important tool in this investigation (Phusavat et al, 2009; Barros et al, 2010).

\section{PERFORMANCE INDICATORS IN TRANS- PORT AND OPERATIONS}

Urban transportation is essential in the context of the modern economy. Plowden and Buchan (1995) show that an efficient urban transport system should offer goods or services to customers at a reasonable cost.

Measures to improve cargo handling in urban areas involve the sharing, participation, and cooperation of shippers, suppliers, transporters, retailers, and customers in the implementation of activities. Therefore, it is necessary to use technologies that align with the reorganization of the entire supply operational processes and organizational elements (Anderson, Allen, \& Browne 2005; Qureshi, Kumar \& Kumar 2008). The use of performance indicators for operation has proven to be a helpful organizational element in overcoming the difficulties in distribution logistics and a good mechanism for business improvement.

Companies already exploit the earning opportunities provided by logistics. However, the evaluation of performance using metrics and indicators is still in the embryonic stage, specifically when the focus is transactions between companies (Gunasekaran, Patel \& Tirtiroglu 2001; Neely, Gregory \& Platts 2005). Without these measures, organizations struggle to analyze whether their strategies are consistent with previously established objectives (Phusavat et al, 2009) and to propose measures that address potential problems with their feasibility (Gunasekaran, Patel \& Tirtiroglu 2001; Barros et al, 2010). Based on a greater understanding of performance metrics, they may review the organizational objectives and re-engineer processes (Neely et al, 2000).

In the case of urban freight transport, Gunasekaran, Patel and Tirtiroglu (2001) relate a number of up- 
stream (suppliers, shippers, wholesalers) as well as downstream (distributors, retailers) delivery factors in the supply chain, such as vehicle speed, driver reliability, frequency of deliveries, and location of deposits with the formation of stock.

In addition, a failure to obtain an optimal location may be considered as a factor if the total cost of the process is less due to gains in other departments, areas, or activities. According to Chen (2008), the total cost approach is most useful in evaluating the performance of distribution activity by including nonfinancial measures that are aligned to the objectives of the firm and oriented towards customers.

Based on the literature review and recommendations of authors, like Neely, Gregory and Platts (2005) and Slack, Chambers and Johnston (2007), the measurement system of this study will use the performance indicators derived from the following operational attributes: Quality, Speed/promptness, Reliability/ consistency, Flexibility and Cost.

As a performance attribute, quality is defined as responsibility to exceed the satisfaction expected by the customer (Neely, Gregory \& Platts, 2005). Promptness in the distribution process is a source of competitive advantage and an important performance attribute. Changes in the logistical process are undesirable and should be addressed in order to achieve greater consistency and reliability with the agreed deadlines (Goldratt \& Cox, 1986). Reliability or consistency, as defined by Slack, Chambers and Johnston (2007), concerns the responsiveness of a company or supply chain in meeting the customer's requirements of confidence in the logistical process.

Flexibility includes the dimension of variety, which is consistent with the ability of a logistical system to be quickly modified to meet a need (Slack, Chambers \& Johnston 2007). Finally, cost is always important in any situation, especially in the urban cargo transport, which is always under pressure due to this attribute.

Based upon the defined importance of performance attributes, we now describe the methodology used to create a system of performance measurement for the urban distribution to small retail food stores in Brazil.

\section{METHODOLOGY}

This is characteristically an inductive study, using both qualitative and quantitative research methods.
Another methodological feature of this study is that it is exploratory in nature, and aims to elucidate those performance attributes that are most relevant to the retail food sector in Belo Horizonte ( 5 million inhabitants in metropolitan area), Brazil.

The data was collected using the survey method to enable a better understanding of the phenomenon. This research intends to create a model of performance measurement based on the scores of indicators and attributes assigned by a group of respondents to generalize the behavior of other members who may not have participated in the survey.

The unit of analysis defined for this study are small retail food stores, more precisely bakeries, grocery stores, and small supermarkets, in the urban area of Belo Horizonte, justified by the guiding question of the work itself. Belo Horizonte's retail sector is engulfed within the urban environment of deteriorating mobility and faces challenges that fall the performance of logistics distribution.

Additionally, the end consumer is the last bond. There is an increasing responsibility to provide services desired by consumers due to the associated threat of customer dissatisfaction, lost sales, decline in revenue, as well as business risk, particularly in the food sector (Ali, 2011).

This study consists of two phases. In the first phase, we administered a semi-structured interview to 15 retail managers in Belo Horizonte, Brazil, based on the stated preference technique. We selected the sample based on researcher intentionality and respondent accessibility. Next, we obtained the distribution management reports of the metropolitan region of Belo Horizonte, and evaluated the retail performance attributes, namely, cost, service, delivery, reliability, and flexibility.

\subsection{Research steps and methods}

The semi-structured interview was administered to 15 managers and entrepreneurs in the urban retail food sector to identify their vision of the logistical distribution of their suppliers in the urban environment, as well as to understand the factors that they consider critical in this process and the measures that need to be taken to improve their satisfaction.

Next, stated preference cards were applied. Li and Hensher (2012) maintain that stated preference is a method to reveal preferences and behaviors based 
on attributes and multiple levels. To identify the relative importance of each characteristic or attribute under evaluation, stated preference enables organizations to adjust their products or services to the customers' wishes. In this case, too, the intent was to capture the ranking of the service attributes through four rounds of interviews of an independent nature, as presumed in the literature. In this manner, these four rounds of interviews yielded 60 independent responses.
The attributes adopted for this research, as proposed by Slack, Chambers and Johnston (2007), are derived from the model that measures the operational performance of urban food retail stores with regard to the logistical distribution of suppliers, as explained in Table 1.

The assembly of the cards for the presentation of alternatives to the respondents depends on the number of attributes and the options available to choose from each attribute. As Figure 1 indicates, this research adopted five attributes and two alternatives for each attribute.

Figure 1 Attributes, levels, and numerical codes used in the Stated Preference

\begin{tabular}{|c|l|c|}
\hline ATTRIBUTE & \multicolumn{1}{|c|}{ LEVELS } & \multicolumn{1}{|c|}{\begin{tabular}{c}
\multicolumn{1}{|c|}{ CODE } \\
Quick: corresponds to shorter order cycles (the period between the execu- \\
tion of the order and the shipment of the items or the start-up of the ser- \\
vice). It implies faster reactions to the surprises offered by the demand. \\
Slow: longer order cycles are not desirable for agencies and entities, since \\
this forces them to make a detailed plan for the demand, which is not \\
always possible due to the emergency nature of some requests (for ex- \\
ample, disease outbreaks, riots).
\end{tabular}} \\
SERVICE & $\begin{array}{l}\text { Satisfactory: customer service is considered effective in terms of both the } \\
\text { information provided and the products delivered or services performed } \\
\text { according to specifications previously made available. } \\
\text { Low: customer service is hampered by the inaccuracy of information, } \\
\text { RELIABILITY }\end{array}$ & $\begin{array}{l}\text { service errors, and contradictions between the contractor and that which } \\
\text { has effectively been provided. } \\
\text { Accuracy of service: customers are certain when they will have their de- } \\
\text { mands met. The agreed time limits are strictly adhered to. } \\
\text { Imprecision of service: users have some level of uncertainty as to when } \\
\text { their demands will be met. } \\
\text { Possibility of changes: the mix of products and services offered, as well } \\
\text { as set times for service, can be changed upon customer's demand. } \\
\text { Changes are not allowed: modifications related to the mix offered, either } \\
\text { in terms of product/service or service hours. } \\
\text { Transactions made at a higher cost to the customer. } \\
\text { Lower cost for distributing products and services. }\end{array}$ \\
\hline
\end{tabular}


In this study, the stated preference technique was used to define the relevant attributes of logistical performance indicators in the urban retail food sector in Belo Horizonte, as well as to highlight the relative importance of each attribute for the urban retail food sector. The process of choosing the cards was a ranking of the alternatives based on the utility of the retail managers.

The next step, following the validation and relativization of the attributes' importance, consisted in the selection of indicators that, in fact, will compose the system of performance measurement. For this research, we used literature review to pre-select 26 indicators related to the attributes cost, service, delivery, reliability, and flexibility.

At first, the same retailers who validated and identified the most important attributes for urban logistical supply operations with regard to their establishments were asked to choose the performance indicators to form the assessment system. However, during the implementation of the stated preference technique, these managers found it difficult to select and identify the function of each indicator. This happened when the performance indicators were shown to the respondents, and they were asked to suggest, criticize, or even exclude an indicator. Perhaps, they have struggled to prioritize the performance indicators of operations to business needs.

The indicators were then presented to the body of experts, Masters and Doctoral students in the Disciplines of Operations of the Graduate Program in Administration, at the Federal University of Minas Gerais, and logistics professionals. They ranked the indicators in the order of priority, assigning a grade of 5 for indicators of high priority, a grade of 3 for those of medium priority, and a grade of 1 for indicators of low priority.

According to Gunasekaran, Patel and Tirtiroglu (2001) and Neely, Gregory and Platts (2005), the number of indicators is an extremely important factor for managers, since excess measures can take the focus away from what really impacts the operation, and should be monitored and evaluated. Thus, 11 indicators were selected to form the performance measurement system for the distribution of food to the micro and small retail sector of Belo Horizonte.

The classification of the indicators followed the ABC criterion, whereby a few items (indicators) reflect the greatest number of cases. Thus, the respondents chose and classified the indicators as follows, as used by Coelho, Martins and Lobo (2013):

- $20 \%$ of the indicators as high priority;

- $30 \%$ of the indicators as medium priority; and

- $50 \%$ of the indicators as low priority.

After the application of indicator questionnaire and achievement of the results, we followed a new classification, based on the sum of the grades for each indicator. At this time, we made a new selection according to the established criteria in order to define the indicators that will compose the measurement system of logistical performance for urban distribution. Finally, we established the performance indicators, and balanced them according to the weight of each defined attribute at the stated preference technique application step.

\subsection{Data analysis}

To analyze the data resulting from the stated preference technique, the multinomial logit model was used. Assuming that the error term of the utility function is governed by a Gumbel distribution, the multinomial logit (Ben-Akiva \& Lerman, 1985) can be written as follows:

$$
P_{n}(i)=\frac{e^{\beta_{k} X_{i n k}}}{\sum_{j \in C} e^{\beta_{k} X_{j n k}}}
$$

in which $P_{n}(i)$ is the probability of the alternative $i$ being chosen by the individual $n$ within a construct of possibilities $C$.

Statistical responses were used for the analysis of the responses by the algorithm developed by Souza (1999).

\section{RESULTS}

\subsection{Validation of attributes and definition of weights}

The technique of application of stated preference cards aims at validating the choice of attributes and defining the relative importance of each attribute in relation to the others to approximate the choice of indicators and the format of the performance measurement system.

In implementing the experiment, it was decided not to present all possible combinations of levels and con- 
structs to respondents, that is, to use the fractional factorial. The obtained results are derived from the ranking by respondents in six groups of five cards, with eight cards using the technique of partially-balanced incomplete groups suggested by Souza (1999). Often, a single repetition of a factorial experiment goes beyond the capabilities of researchers, or provides more precision than needed for the estimation of the main effects (Cochran and Cox 1978).

The use of fractional repeat experiments was proposed by Finney (1945). Since then, these experiments have been used in many applications, es- pecially in industrial development. Their main attraction is that they allow the inclusion of five or more factors in an experiment of practical size, so that the researcher can quickly determine the effects of the factors in the outcome.

The parameter estimation was based on the multinomial logit model with conditional probability (Table 1). As a premise, the multinomial logit model defines the preferences of the retailers as homogeneous. The estimators of the attributes represent the marginal utility of each attribute and provides it with an equal meaning (Marcucci \& Gatta, 2012).

\section{Table 1 Stated preference result LMPC model}

\begin{tabular}{l|cccc}
\hline \multicolumn{1}{c|}{ Attribute } & Coefficient & Error & T test & IC (t=25\%) \\
Flexibility & 0.1784 & 0.2309 & 0.7728 & {$[-0.283 ; 0.640]$} \\
Delivery & 1.1426 & 0.2565 & 4.4540 & {$[0.630 ; 1.656]$} \\
Cost & 1.4939 & 0.2478 & 6.0286 & {$[0.998 ; 1.990]$} \\
Service & 1.4658 & 0.2407 & 6.0910 & {$[0.985 ; 1.947]$} \\
Reliability & 0.9695 & 0.2423 & 4.0013 & {$[0.485 ; 1.454]$}
\end{tabular}

Number of interviews $=60 \quad$ Number of cases $=180$

$\mathrm{Rho}=0.3486 \quad$ Rho $($ Ajt $)=0.3224$

The analysis of the results reveals that the cost attribute displayed the greatest relative importance among the five selected attributes, with a coefficient of 1.4939. This means that bakeries, grocery stores, and small supermarkets in the sample perceive the predominant importance of the cost attribute. The service attribute was second in level of importance to those surveyed, with a parameter of 1.4658 , very close to the cost parameter. Next, among the attributes of the operation of the urban distribution of food, delivery (1.1426) and reliability (0.9695) were most important. The least important among the five attributes was flexibility in the logistical operation.

Based on the criterion of representativeness, which considers the weight of each attribute in relation to the total value of the coefficients, the cost attribute obtained $28.45 \%$ of the total weight of the coefficients. This was followed by the service attribute, which showed a relative weight of $27.92 \%$, the delivery attribute at $21.76 \%$, reliability at $18.47 \%$, and flexibility at $3.40 \%$.
The next step analyzed the significance of each parameter or attribute according to a model. The LMPC software (Souza, 1999) used considers the $t$-test with a significance level of $95 \%$ for these parameters. To perform this analysis, Hair et al. (2005) argue that a good measure of significance for the t-test is to consider values greater than one standard deviation, or 1.96. Therefore, attributes above this measure are statistically different from 0 . The attributes with a $t$ measurement below 1.96 are statistically equal to 0 .

All the parameters under consideration differed significantly from zero, with the exception of flexibility. This claim that they are different from zero can be made with $95 \%$ certainty [delivery, with a t-test of (4.4540), cost (6.0286), service (6.0910), and reliability (4.0013)]. However, flexibility in the logistical distribution of food products in the urban area of Belo Horizonte could not be considered as an attribute significantly different from zero with 95\% certainty, as its t-statistic score is 0.7728 . Therefore, this attri- 
bute was removed from the elaboration of the performance measurement system.

The reliability construct has a higher correlation coefficient, indicating a very strong correlation, which means that the population sampled places a lot of importance upon this attribute, and that the attribute of flexibility has less importance statistically because its correlation coefficient is very weak. According to Shikimura (2006), a very strong association exists at values of 0.90 and 1.00 and a very weak correlation at values between 0.00 and 0.19 .

According to the approach taken in the urban freight transport literature, cost still emerged as the main attribute in the formation of urban retailers' expectations, and therefore, a key point in planning a logistical operation or a city's urban roads. However, the results of this study indicate that, at least with regard to the micro and small retail food segment in the capital of Minas Gerais, cost should not be considered as the only important factor for evaluating the performance of a distribution operation in an urban environment.

This result corroborates with Morgan and Hunt (1994), Johnson and Grayson (2000), and Lindgreen (2003), who highlight the importance of intra- and inter-organizational relationships along the supply chain in search of cooperation, credibility, and trust among partners to increase the efficiency of the operation or process, and improve the profitability of the entire chain. These studies consider that the gains, thus achieved, are measured in terms of the reduction of opportunistic behavior, the elimination of predatory bargaining power, and the reduction of transaction costs and the switching of vendors.

Together, the relative importance of the service, reliability, and delivery attributes in the operation of retail supply was around $70 \%$. The result may be explained by the impact of the lack of products on the shelves (stockout) on retail performance (Woensel et al, 2007; Aastrup \& Kotzab, 2009, 2010).

\subsection{Definition of performance indicators}

We originally utilized 26 indicators obtained from Bowersox, Closs and Cooper (2002), Ballou (2004), Slack, Chambers and Johnston (2007) and Neely, Gregory and Platts (2005).

However, as the application of the stated preference technique revealed no significance for the flexibility attribute in the evaluation model of the proposed logistical performance, the final list comprised 22 indicators.

Fifteen of the 18 experts provided responses, representing $80 \%$ of the experts' population. The indicator was graded at 5 if the expert defined it as a high priority, 3 if defined a medium priority, and 1 if defined a low priority.

Table 2 describes the set of indicators defined for the system. 
Table 2 Indicators proposed for the performance measuring system of the food distribution operation in the retail sector of Belo Horizonte

\begin{tabular}{|c|c|c|c|}
\hline ATTRIBUTE & INDICATOR & DEFINITION & FÓRMULA \\
\hline \multirow{3}{*}{ SERVICE } & $\begin{array}{l}\text { Product /service according to specifi- } \\
\text { cations }\end{array}$ & $\begin{array}{l}\text { Product delivered or service performed according to } \\
\text { specifications. }\end{array}$ & $\begin{array}{l}\text { Semantic differential scale of six points - ex- } \\
\text { tremes: from fully compliant to divergent. }\end{array}$ \\
\hline & $\begin{array}{l}\text { Service quality (agile confirmation, } \\
\text { friendliness, promptness) }\end{array}$ & $\begin{array}{l}\text { Customer perception of service quality (from elec- } \\
\text { tronic to personal contact) }\end{array}$ & $\begin{array}{l}\text { Semantic differential scale of six points }- \text { ex- } \\
\text { tremes: from poor to optimal. }\end{array}$ \\
\hline & Returns & $\begin{array}{l}\text { Percentage of returned products or unapproved } \\
\text { services within a proposed period to the total num- } \\
\text { ber of products delivered and services performed } \\
\text { during the period. }\end{array}$ & $\begin{array}{l}\text { Sum of the number of returned products or unap- } \\
\text { proved services by the customer/Total number of } \\
\text { products delivered and services performed during } \\
\text { the period. }\end{array}$ \\
\hline \multirow{3}{*}{ RELIABILITY } & Complete orders & $\begin{array}{l}\text { Percentage of orders delivered whose requests were } \\
\text { fully met (mix and quantity) for the number of or- } \\
\text { ders placed during the period. }\end{array}$ & $\begin{array}{l}\text { Number of complete orders filled/Total number of } \\
\text { orders placed during the period. }\end{array}$ \\
\hline & Product integrity & $\begin{array}{l}\text { Percentage of products delivered undamaged in rela- } \\
\text { tion to the total number of products delivered in the } \\
\text { period. }\end{array}$ & $\begin{array}{l}\text { Number of products delivered undamaged/Total } \\
\text { number of products delivered in the period. }\end{array}$ \\
\hline & Complaints regarding orders & $\begin{array}{l}\text { Percentage of orders delivered whose requests were } \\
\text { not fully met (assortment or quantity) for the number } \\
\text { of orders placed during the period. }\end{array}$ & $\begin{array}{l}\text { Number of orders serviced with a complaint/Total } \\
\text { number of orders placed during the period. }\end{array}$ \\
\hline \multirow{2}{*}{ COST } & $\begin{array}{l}\text { Percentage of the transport cost in } \\
\text { sales }\end{array}$ & Share of total transport costs in relation to sales. & Total shipping cost/revenue earned through sales. \\
\hline & Cost of out-of-stock products for sale & $\begin{array}{l}\text { Measurement of the loss of profitability by the ab- } \\
\text { sence of inventory to meet demand. }\end{array}$ & $\begin{array}{l}\text { Semantic differential scale of six points }- \text { ex- } \\
\text { tremes: from no loss to significant loss. }\end{array}$ \\
\hline \multirow{3}{*}{ DELIVERY } & Average length of order delay & $\begin{array}{l}\text { Average length of delay after the deadline estab- } \\
\text { lished for the order's submission. }\end{array}$ & $\begin{array}{l}\text { (Time in day and hour of receipt of the product or } \\
\text { initiation of service) - (time in day and hour previ- } \\
\text { ously established for order fulfillment) }\end{array}$ \\
\hline & Length of the order cycle & $\begin{array}{l}\text { Length of time between placing the order and its ac- } \\
\text { tual delivery. }\end{array}$ & $\begin{array}{l}\text { (Day and hour of submission of the order) - (Day } \\
\text { and hour of order placement by the customer) }\end{array}$ \\
\hline & $\begin{array}{l}\text { Waiting time for receipt of the com- } \\
\text { plaint }\end{array}$ & $\begin{array}{l}\text { Time elapsed since the identification of a delivery } \\
\text { complaint until its correction (complementation). }\end{array}$ & $\begin{array}{l}\text { (Time in day and hour of the receipt of the item } \\
\text { of complaint) - (time in day and hour when the } \\
\text { complaint was identified) }\end{array}$ \\
\hline
\end{tabular}




\section{FINAL CONSIDERATIONS}

The issue of urban mobility motivated this study, which aims to define the most important attributes to evaluate the performance of the logistical operation for retail supply.

Urban mobility in large urban centers has decreased considerably in recent years, deteriorating the quality of life and level of logistical supply service to companies in those areas. In this framework, we define the small retail food stores in Belo Horizonte, Brazil, as the unit of analysis for the proposal to develop a system to evaluate the performance of suppliers and carriers in the logistical operation of supply in these stores. The study focuses on the logistical operation of food supply due to the complexity involved in the delivery of perishable and fragile foods. Thus, quality in this type of operation is critical and measurement of the performance of activities becomes essential for companies included in this supply chain.

The performance measurement system enables the measurement and control of the activities. Moreover, its systematic use would result in a cycle of continuous improvement in the food supply chain, thereby providing a higher quality of service to retail stores, and consequently, to the end consumer. Furthermore, the proposed system helps identify problems and can be seen as a tool for integration.

Another noteworthy point of this study is the determination of importance of the attributes related to the service level. The high degree of relevance achieved by the attributes that define the service level may indicate bottlenecks and current critical points in services. This means that gaps in services, such as delays in delivery or failure to deliver completed items of an order, compromise the availability of products on the shelves and this situations of stockout has serious implications for the retail store in relation to the customer. At the same time, compensatory practices of stock build-up are financially very burdensome or unviable in terms of storage area.

As a limitation of this study, it can be understood that the retail segment under study has some peculiarities. Furthermore, the experiment was conducted in Belo Horizonte, Brazil, which also has its own unique qualities.

However, despite these limitations, it is evident that the model's gradual development tests logistics, while also contributing to the suggestion of the use of Stated Preference for more assertive positions concerning attributes and their relative importance. Thus, this study contributes to business management by developing a tool for control and performance monitoring. Its constant use will enable the creation of a cycle of continuous improvement, with the establishment of goals, research on problems, and proposal of solutions.

Another possible application of the proposed system is for boards of management and regulation as an indicator of urban mobility, because retailer satisfaction with the operation of their suppliers and carriers is linked to traffic conditions and cargo handling in urban centers (Kohler, 1997; Taniguchi, Heijden \& Van Der, 2000; Kohler, 2001, Taniguchi, Thompson \& Yamada, 2001, Taniguchi et al, 2001; Stewart, 1995; Hsu, Kannan \& Leong, 2008).

\section{REFERENCES}

AASTRUP, J.; KOTZAB, H. (2009) Analyzing out-of-stock in independent grocery stores: an empirical study. International Journal of Retail \& Distribution Management. 37:765-789.

(2010) Forty years of out-of-stock research - and the shelves are still empty. The International Review of Retail, Distribution and Consumer Research. 20:147-164.

ALI, S. S. (2011) Redefining retailers satisfaction Index: A Case Of Nestle India Ltd. In: 22nd Annual Conference of Production \& Operation Management Society, 2011, Peppermill Resort Spa Casino, Reno, Nevada, U.S.A. Proceedings... Peppermill Resort Spa Casino, Reno, Nevada, U.S.A.

ANDERSON, S.; ALLEN, J.; BROWNE, M. (2005) Urban logistics - how can it meet policy makers' sustainability objectives? Journal of Transport Geography, 13: 71-81.

BALLOU, R. H. (2004) Business Logistics: Supply Chain Management. $5^{\text {th }}$ Edition, Upper Saddle River, New Jersey: Pearson-Prentice Hall.

BARROS, A. C.et al. (2010) A framework for evaluating firm-level supply chain performance. In: $17^{\text {th }}$ International Annual EurOMA Conference. Proceedings..., Porto, Portugal.

BEN-AKIVA, M., LERMAN, S. R. (1985) Discrete Choice Analysis: Theory and application to travel demand. New Jersey, Mit Press.

BOWERSOX, D. J.; CLOSS, D. J.; COOPER, M. B. (2002) Supply Chain Logistics Management. McGraw-Hill, New York. (Series Operations and Decision Sciences)

CHEN, C. C. (2008) model for customer-focused objective-based performance evaluation of logistics service providers. Asia Pacific Journal of Marketing and Logistics, 20: 309-322.

CHOPRA, S.; MEINDL, P. (2007) Supply Chain Management: Strategy, Planning, and Operations. $3^{\text {rd }}$ ed., Upper Saddle River, New Jersey: Pearson Education, Inc. 
COCHRAN, William G.; COX, Gerturude M. Diseños Experimentales. México : Trillas, 1978

COELHO, R. R; MARTINS, R.S.; LOBO, D.S. (2013) Desenvolvimento de Modelo de Avaliação de Desempenho: Aplicação a um Centro de Serviços Compartilhados. Revista Portuguesa e Brasileira de Gestão, 12: 69-80.

FINNEY, D.J. (1945) The fractional replication of factorial arrangement". Ann. Eugen. 12, p. 291-301.

GOLDRATT, E. M.; COX, J. (1986) The goal: beating the competition. Hounslow.

GUNASEKARAN, A.; PATEL, C.; TIRTIROGLU, E. (2001) Performance measures and metrics in a supply chain environment. International Journal of Operations \& Production Management, 21: 71-87.

HAIR, J.F.; ANDERSON, R.E.; TATHAM, R.L.; BLACK, W. C. (2005) Multivariate Data Analysis, Upper Saddle River, NJ: Prentice Hall.

HSU, C.; KANNAN, V.; LEONG, K. (2008) Information sharing, buyer-supplier relationships, and firm performance. International Journal of Physical Distribution \& Logistics Management, 38: 296-310.

JOHNSON, D.; GRAYSON, K. (2000) Sources and Dimensions of Trust in Service Relationships. IACOBUCCI, D.; SWARTZ, T. Handbook of Services Marketing, Thousand Oaks, CA: Sage, 357-370.

KOHLER, U. (1997) An innovating concept for city-logistics. In: Proceedings 4th World Congress on Intelligent Transport Systems, 1997, Berlin, Germany. Proceedings... Berlin, Germany.

KOHLER, U. (2001) How to change urban traffic with city logistics. In: Schneider, E., Becker, U. (Ed.). Control in transportation systems, Pergamon, Oxford, p.199-201.

LI, Z.; HENSHER, D. A. (2012) Congestion charging and car use: a review of stated preference and opinion studies and market monitoring evidence. Transport Policy, 20: 47-61.

LINDGREEN, A. (2003) Trust as valuable strategic variable in the food industry: Different types of trust and their implementation. British Food Journal, 105: 310-327.

LOUVIERE, J. J.; HENSHER, D. A.; SWIAT, J. D. (2000). Stated Choice Methods: analysis and application. $1^{\text {st }}$ ed. Cambridge: Cambridge University Press.

MARCUCCI, E.; GATTA, V. (2012) Dissecting preference heterogeneity in consumer stated choices. Transportation Research Part E: Logistics and Transportation Review, 48: 331-339.
MORGAN, R.M.; HUNT, S.D. (1994) The commitment-trust theory of relationship marketing. Journal of Marketing, 58: 20-38.

NEELY, A.; GREGORY, M.; PLATTS, K. (2005) Performance measurement system design: a literature review and research agenda. International Journal of Operations \& Production Management, 25:1.228-63.

NEELY, A. et al. (2000) Performance measurement system design: developing and testing a process-based approach. International Journal of Operations \& Production Management, 20: 1.119-45.

ORTÚZAR, J. D. (1998). Modelos de demanda de transporte. 2nd ed. Santiago: Ediciones Universidad Católica de Chile.

PHUSAVAT, K. et al. (2009) Performance measurement: roles and challenges. Industrial Management \& Data Systems, 109: 646-64.

PLOWDEN, S.; BUCHAN, K. (1995) A new framework for freight transport. London.

QURESHI, M. N.; KUMAR, D.; KUMAR, P. (2008) An integrated model to identify and classify the key criteria and their role in the assessment of 3PL services providers. Asia Pacific Journal of Marketing and Logistics, 20: 227-249.

SLACK, N.; CHAMBERS, S.; JOHNSTON, R. (2007) Operations Management. $5^{\text {th }}$ Ed. Harlow: FT Prentice Hall.

SOUZA, O. A. (1999) Delineamento experimental em ensaios fatoriais utilizados em preferência declarada, Florianópolis, UFSC. (Tese - Doutorado em Engenharia de Produção/Universidade Federal de Santa Catarina)

STEWART, G. (1995) Supply chain performance benchmarking study reveals keys to supply chain excellence. Logistics Information Management, 8: 38-44.

TANIGUCHI, E.; HEIJDEN, R. E.; VAN DER, C. M. (2000) An evaluation methodology for city logistics. Transport Reviews, 20: 65-90.

TANIGUCHI, E.; THOMPSON, R. G.; YAMADA, T. (2001) Recent advances in modelling city logistics. In: TANIGUCHI, E.;THOMPSON, R. G. et al (Ed.). City Logistics II.. Kyoto: Institute of Systems Science Research. pp. 3-33.

TANIGUCHI, E. et al. (2001) City Logistics: network modelling and intelligent transport systems. Oxford: Pergamon, 2001.

WOENSEL, T.; DONSELAAR, K., BROEKMEULEN, R.; FRANSOO, J. (2007) Consumer responses to shelf out-of-stocks of perishable products, International Journal of Physical Distribution \& Logistics Management, 37: 704-718. 


\section{AUTHOR'S BIOGRAPHY:}

João Victor Rodrigues Silva: is an Economist and received his Master Degree in Administration from the Center for Graduate Studies and Research in Business Administration, Federal University of Minas Gerais (UFMG), Brazil. His research interests include urban distribution, transport systems and Regional development and transportation.

Ricardo Silveira Martins: Doctor in Applied Economics from the University of São Paulo. Lecturer at UFMG. Teaches and carries out research in Operations and Logistics Management at the Post-Graduate Centre for Research in Management. One of the leaders of the Interdisciplinary Centre for Research in Logistics. Areas of activity: Supply Chain Logistics, Logistics in Small and Medium-sized Companies and Logistic Strategies. 